\title{
PRACTICE
}

- This series of articles is designed to aid in the orthodontic evaluation of patients

- Not every malocclusion needs orthodontic treatment

- Not every patient is suitable for treatment

- Understanding the treatment benefit for the patient is important

- GDPs have an important role to play in assessing the need for orthodontic treatment

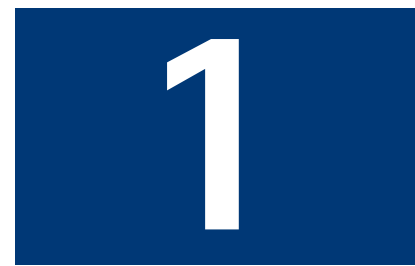

VERIFIABLE

CPD PAPER

\section{Orthodontics. Part 1: Who needs orthodontics?}

\author{
D. Roberts-Harry ${ }^{1}$ and J. Sandy ${ }^{2}$
}

ORTHODONTICS
1. Who needs
orthodontics?
2. Patient assessment and
examination I
3. Patient assessment and
examination II
4. Treatment planning
5. Appliance choices
6. Risks in orthodontic
treatment
7. Fact and fantasy in
orthodontics
8. Extractions in
orthodontics
9. Anchorage control and
distal movement
10. Impacted teeth
11. Orthodontic tooth
movement
12. Combined orthodontic
treatment

${ }^{1 *}$ Consultant Orthodontist, Orthodontic Department, Leeds Dental Institute,

Clarendon Way, Leeds LS2 9LU; ${ }^{2}$ Professor in Orthodontics, Division of Child Dental Health, University of Bristol Dental School, Lower Maudlin Street, Bristol BS1 2LY ${ }^{*}$ Correspondence to: D. Roberts-Harry E-mail: robertsharry@btinternet.com

\section{Refereed Paper}

doi:10.1038/sj.bdj.4810592

๑ British Dental Journal 2003; 195:

433-437

There are various reasons for offering patients orthodontic treatment. Some of these include improved aesthetics, occlusal function and the long-term dental health.

Orthodontics comes from the Greek words 'orthos' meaning normal, correct, or straight and 'dontos' meaning teeth. Orthodontics is concerned with correcting or improving the position of teeth and correcting any malocclusion. What then do we mean by occlusion and malocclusion? Surprisingly the answer is not straightforward. There have been various attempts to describe occlusion using terms such as ideal, anatomic (based on tooth morphology), average, aesthetic, adequate, normally functioning and occlusion unlikely to impair dental health.
With these different definitions of what constitutes malocclusion, there is, not surprisingly a degree of confusion as to what should be treated and what should not. Although some tooth positions can produce tooth and soft tissue trauma, it is important to remember that malocclusion is not a disease but simply a variation in the normal position of teeth. Essentially, there are three principal reasons for carrying out orthodontic treatment:

1. To improve dento facial appearance 2. To correct the occlusal function of the teeth

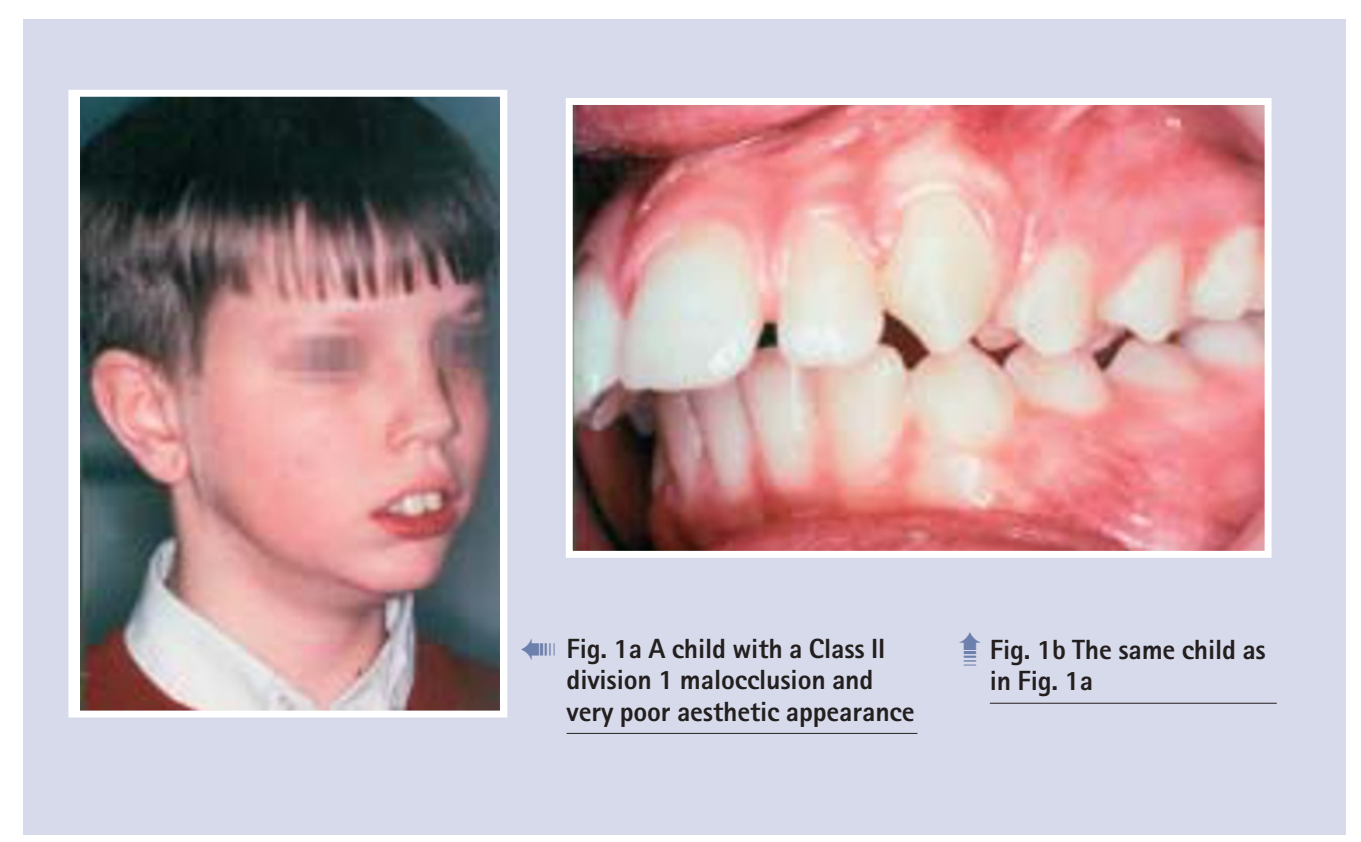




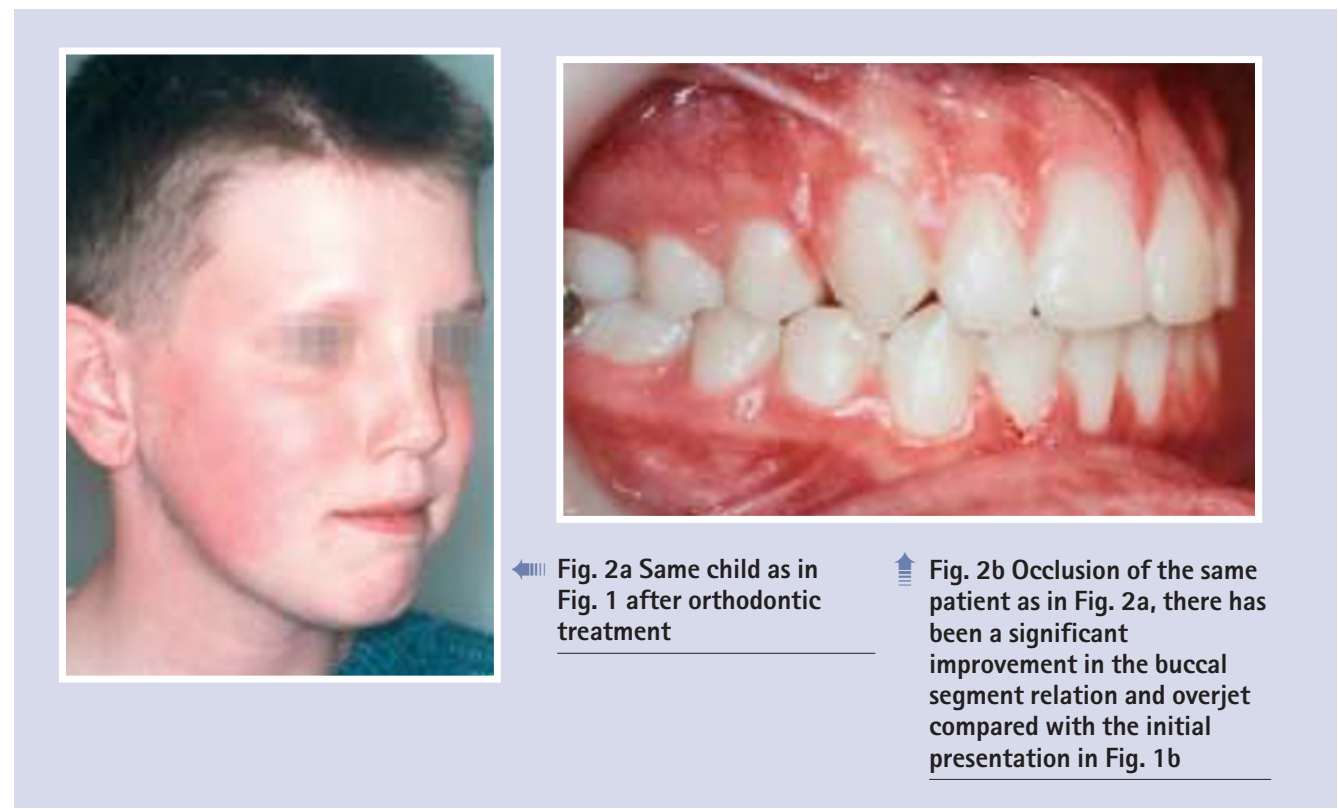

\begin{tabular}{lc}
$\begin{array}{l}\text { Table } 1 \text { Features children most dislike or are teased } \\
\text { about (Shaw et al. }{ }^{1} \text { ) }\end{array}$ \\
\hline Feature & $\begin{array}{c}\text { Disliked appearance } \\
\text { or teased (\%) }\end{array}$ \\
\hline Teeth & 60.7 \\
Clothes & 53.8 \\
Ears & 51.7 \\
Weight & 41.5 \\
\hline Brace & 33.3 \\
Nose & 29.3 \\
\hline Height & 25.3 \\
\hline
\end{tabular}

3. To eliminate occlusion that could damage the long-term health of the teeth and periodontium

\section{DENTO FACIAL APPEARANCE}

Improving the appearance of the teeth is without question the main reason why most orthodontic treatment is undertaken. Although it might be tempting to dismiss this as a trivial need, there is little doubt that a poor dental appearance can have a profound psychosocial effect on children. Figure 1 illustrates such a case with a child who has a substantial aesthetic need for treatment. The case is shown before (Fig. 1a, b) and after (Fig 2a, b) orthodontic treatment. Few would question that there has been an improvement in both the dental and facial appearance of this child. Indeed, orthodontic treatment can have a beneficial psychosocial effect. For example Shaw et al. ${ }^{1}$ found that children were teased more about their teeth than anything else, such as the clothes they wear or their weight and height (Table 1).

Fig. 3 This patient has a severe anterior open bite with contact only on the molars

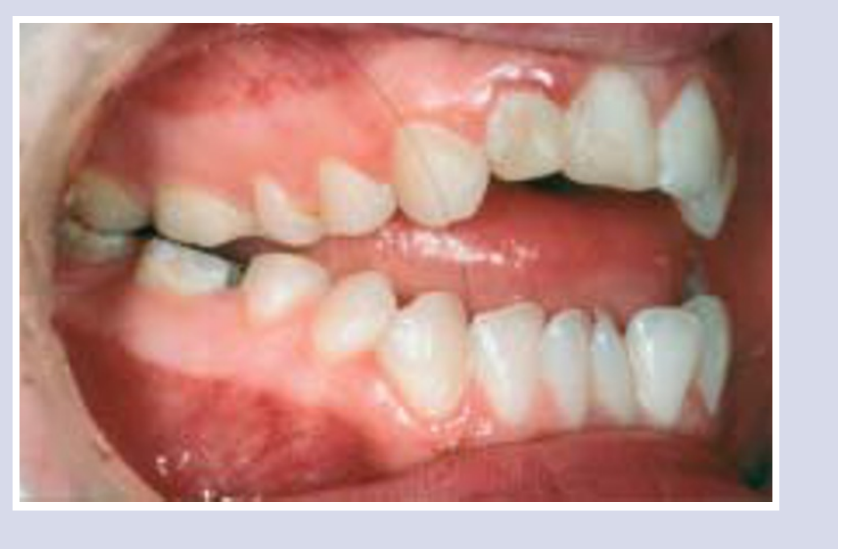

\section{OCCLUSAL FUNCTION}

Teeth, which do not occlude properly, can make eating difficult and may predispose to temporomandibular joint (TMJ) dysfunction. However, the association with TMJ dysfunction and malocclusion is a controversial subject and will be discussed in more detail in a later section. Individuals who have poor occlusion, such as shown in Figure 3, may find it difficult and embarrassing to eat because they cannot bite through food using their incisors. They can only chew food using their posterior teeth.

\section{DENTAL HEALTH}

Fig. 4 Class II Division 1 with an increased overjet. The anterior teeth are at risk of potential trauma with an overjet of $10 \mathrm{~mm}$ or greater

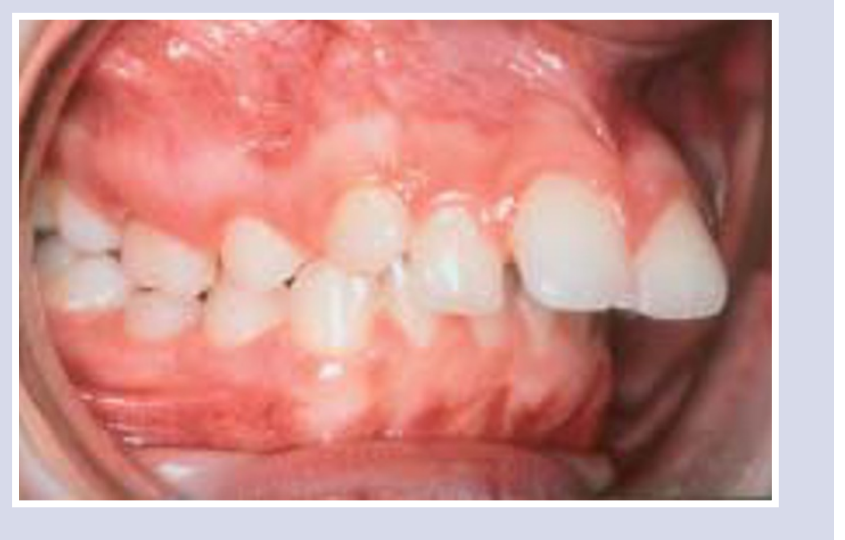

Surprisingly there is no strong association between dental irregularity and dental caries or periodontal disease. It seems that dietary factors are much more important than the alignment of the teeth in the aetiology of caries. Although straight teeth may be easier to clean than crooked ones, patient motivation and dental 
hygiene seems to be the overriding factor in preventing gingivitis and periodontitis. That said, few of the studies that have investigated the link between crowding and periodontal disease have been longitudinal, over a long term and included older adults. It would appear that aligned teeth confer no benefit to those who clean their teeth well because they can keep their teeth clean regardless of any irregularity. Similarly, alignment will not help bad brushers. If there is poor tooth brushing, periodontal diseases will develop no matter how straight the teeth are. However, having straight teeth may help moderate brushers, although there is no firm evidence to support or refute this statement. This is an area that requires further study.

Some malocclusions may damage both the teeth and soft tissues if they are left untreated. It is well known that the more prominent the upper incisors are the more prone they are to trauma ${ }^{2,3}$ (Table 2).

When the overjet is $9 \mathrm{~mm}$ or more the risk of damaging the upper incisors increases to over $40 \%$. Reducing a large overjet is not only beneficial from an aesthetic point of view but minimises the risk of trauma and long-term complications to the dentition. Fig. 4 shows a child with a large overjet and it is not difficult to imagine the likely dental trauma that would result if he or she fell over.

\begin{tabular}{cc}
$\begin{array}{l}\text { Table } 2 \text { Relation between size of overjet and } \\
\text { prevalence of traumatised anterior teeth }\end{array}$ \\
\hline Overjet $(\mathrm{mm})$ & Incidence $\%$ \\
\hline 5 & 22 \\
9 & 24 \\
$>9$ & 44 \\
\hline
\end{tabular}

Certain other occlusal relationships are also liable to cause long-term problems. Figure 5a and $\mathrm{b}$ show a case where there is an anterior cross-bite with an associated mandibular displacement in a 60-year-old man. The constant attrition of the lower incisors against the upper when the patient bites together, have produced some substantial wear. If allowed to continue then the long-term prognosis for these teeth is extremely poor. In order to preserve the teeth, the patient accepted fixed appliance treatment that eliminated the cross bite and helped prevent further wear Figure $5 c$ and d.

Another example of problems caused by an anterior cross bite is shown in Figure 6. A traumatic anterior occlusion produced a displacing force on the lower incisors with apical migration of the gingival attachment as a consequence. Provided this situation is remedied early (Fig. 7) the soft tissue damage stops and as the rest of the gingivae matures the situation often resolves

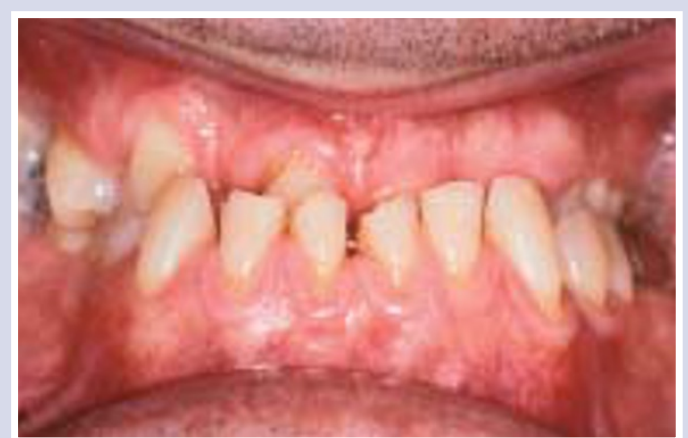

Fig. 5a Anterior crossbite in a 60 -year-old man occluding in the intercuspal position

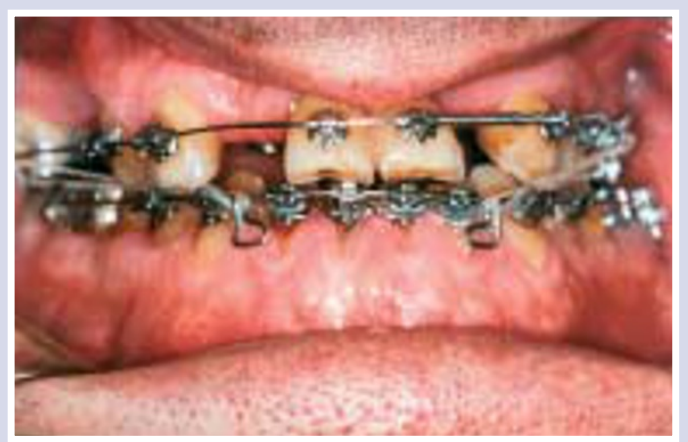

Fig. 5c The patient in fixed appliances in order to correct the displacement and the position of his upper anterior teeth

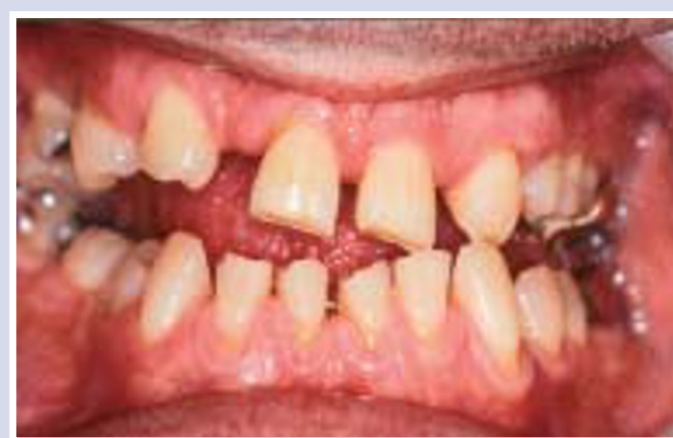

Fig. $5 b$ Shows the retruded contact position of the patient. To reach full intercuspation the mandible displaces forward and this movement is probably associated with the wear on the incisors

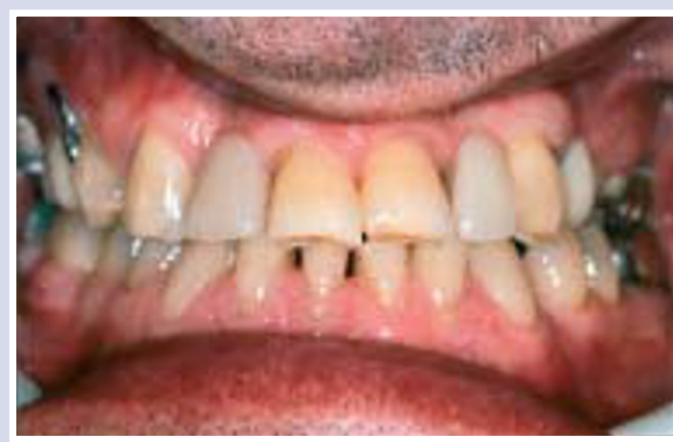

Fig. $5 \mathrm{~d}$ After correction and space reorganisation the patient is wearing a prosthesis to replace the missing lateral incisors 

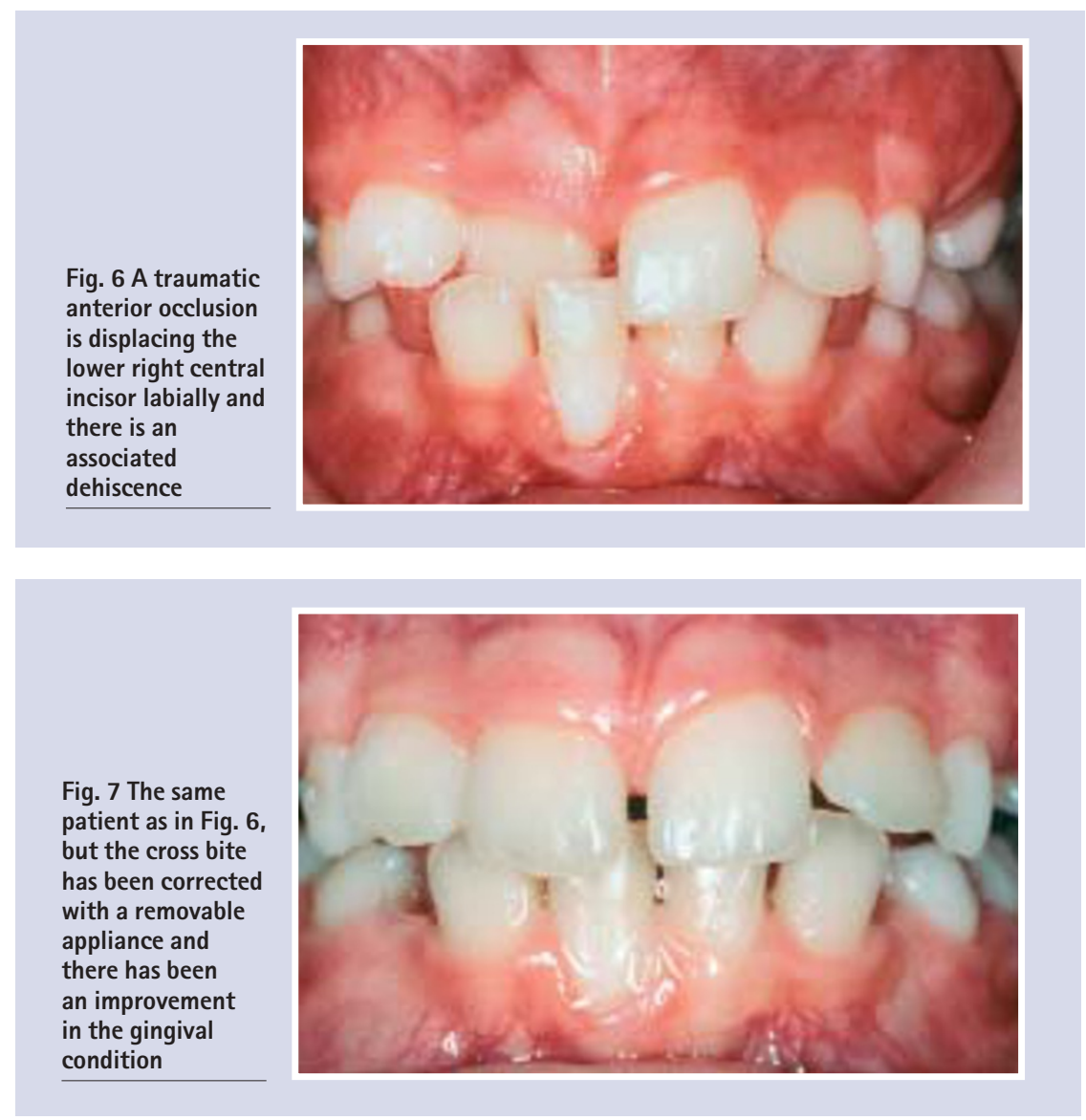

spontaneously and no long-term problems usually develop.

Deep overbites can occasionally cause stripping of the soft tissues as shown in Figure 8a and $b$. This is a case where there is little aesthetic need for treatment but because of the deep overbite there is substantial damage to the soft tissues. Clearly if this is allowed to continue there is a risk of early loss of the lower incisors that would produce a difficult restorative problem.

\section{WHO SHOULD BE TREATED?}

Dental irregularity alone is not an indication for treatment. Most orthodontic treatment is carried out for aesthetic reasons and the benefit an indi- vidual will receive from this will depend on the severity of the presenting malocclusion as well as the patients own perception of the problem. Some individuals can have a marked degree of dento-facial deformity and be unconcerned with their appearance. Although a practitioner may suggest treatment for such an individual, patients should not be talked into treatment and must be left to make the final decision themselves. Mild malocclusions should be treated with caution. Not only will the net improvement in the appearance of the teeth be small, but also as nearly all teeth move to some degree after orthodontic treatment the risk of relapse in these cases is high. Whilst minor movements after the correction of severe malocclusions will still produce a substantial net overall improvement for the patients, the same is not true of minor problems. Many practitioners will have encountered the parent who can spot a 5-degree rotation of an upper lateral incisor from fifty metres and is convinced this will be the social death of their child. Regardless of how insistent the parent or child is, the practitioner should approach such problems

\begin{tabular}{cl}
\hline \multicolumn{3}{l}{ Table 3 Index of Treatment Need } \\
\hline Dental health component & Treatment need \\
\hline 1 & No need \\
\hline 2 & Little need \\
\hline 3 & Moderate need \\
\hline 4 & Great need \\
\hline 5 & Very great need \\
\hline Aesthetic component & Treatment need \\
\hline 1 & \\
\hline 2 & Little need \\
\hline 3 & \\
\hline 4 & \\
\hline 5 & Moderate need \\
6 & \\
\hline 7 & \\
\hline 8 & Great need \\
\hline 9 & \\
\hline 10 & \\
\hline
\end{tabular}

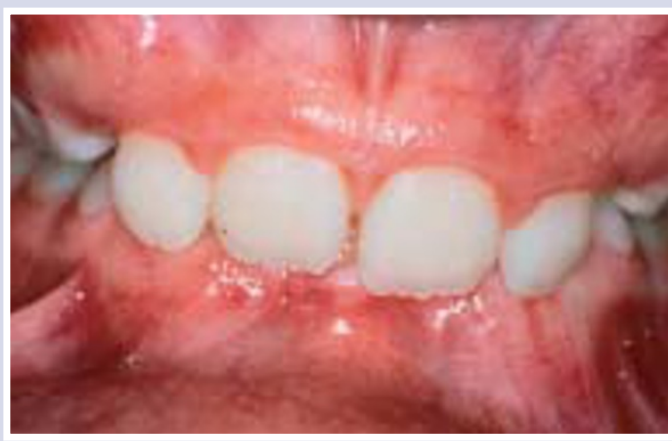

Fig. 8a This malocclusion has an extremely deep bite which can be associated with potential periodontal problems

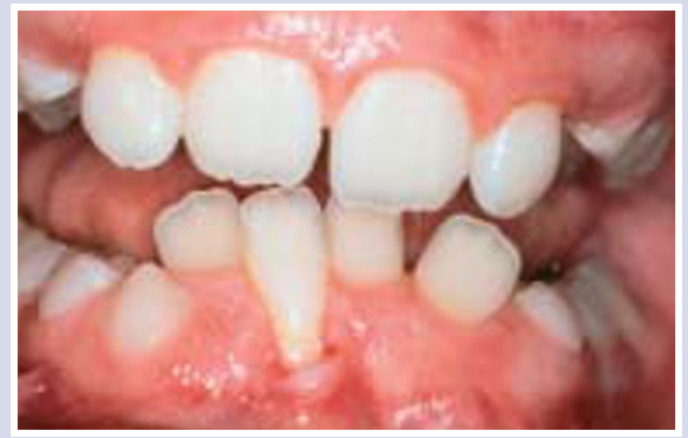

Fig. $8 \mathrm{~b}$ The same patient as in Fig. $8 \mathrm{a}$, but not in occlusion. The deep bite has resulted in labial stripping of the periodontium on the lower right central incisor 
with care and only carry out the treatment if it is in the best interests of the patient. It is essential that the patient and parent are fully aware of the limitations of treatment and that long term, ie permanent retention is currently the only way to ensure long-term alignment of the teeth.

In order to assess the need for orthodontic treatment, various indices have been developed. The one used most commonly in the United Kingdom is the Index of Orthodontic Treatment Need (IOTN). ${ }^{4}$ This index attempts to rank malocclusion, in order, from worst to best. It comprises two parts, an aesthetic component and a dental health component (Table 3). The aesthetic component consists of a series of ten photographs ranging from most to least attractive. The idea is to match the patient's malocclusion as closely as possible with one of the photographs. It is unlikely that a perfect match will be found but the practitioner should use his or her best guess to match to the nearest equivalent photograph. The dental health component consists of a series of occlusal traits that could affect the long-term dental health of the teeth. Various features are graded from 1-5 (least severe - worst). The worst feature of the presenting malocclusion is matched to the list and given the appropriate score.

Many hospital orthodontic services will not accept patients in categories 1-3 of the dental health component or grade 6 or less of the aesthetic component of the IOTN unless they are suitable for undergraduate teaching purposes.

Whilst the IOTN is a useful guide in prioritising treatment and determining treatment need it

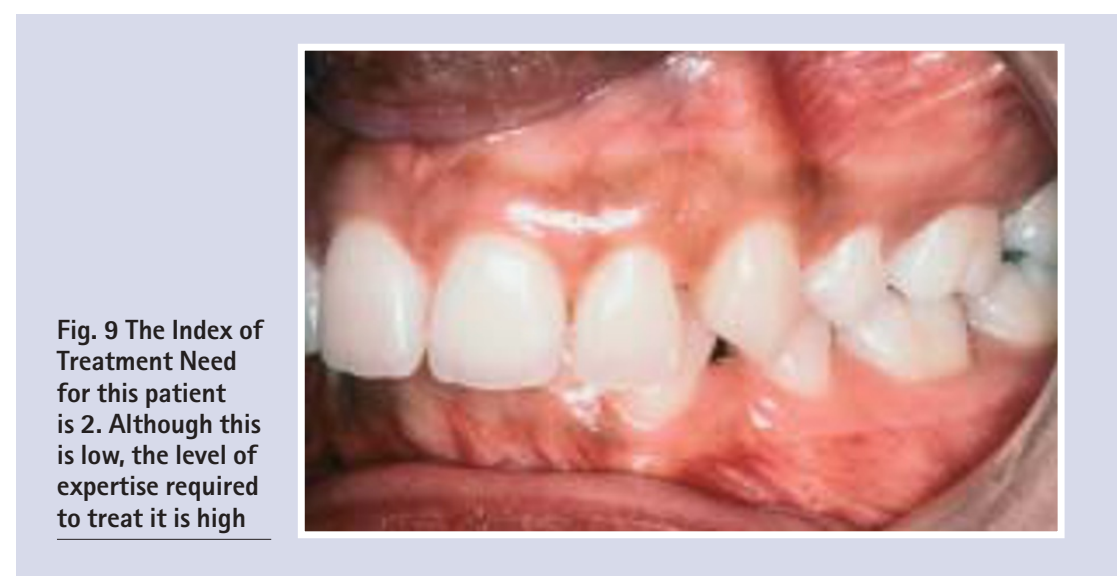

takes no account of the degree of treatment difficulty. For example, class II division 2 malocclusions are notoriously difficult to treat yet they might have a low IOTN. Figure 9 illustrates such a case. The IOTN of this patient is only 2 but it is a difficult case to manage and treatment requires a high level of expertise.

1. Shaw W C, Meek S C, Jones D S. Nicknames, teasing, harassment and the salience of dental features among school children. Br J Orthod 1980; 7: 75-80.

2. Office of Population Censuses and Surveys (1994). Children's dental health in the United Kingdom 1993. London: HMSO 0116916079.

3. Office of Population Censuses and Surveys (1985). Children's dental health in the United Kingdom 1983. London: HMSO 0116911360.

4. Brook P, Shaw W C. The development of an index of orthodontic treatment priority. Eur J Orthod 1989; 11 : 309-320. 